\title{
Profile of sleep disordered breathing in heart failure with preserved ejection fraction
}

\author{
Nitesh Gupta ${ }^{1}$, Sumita Agrawal ${ }^{2}$, Akhil D. Goel ${ }^{3}$, Pranav Ish ${ }^{1}$, Shibdas Chakrabarti' ${ }^{1}$ J.C. Suri ${ }^{4}$ \\ ${ }^{1}$ Department of Pulmonary, Critical Care and Sleep Medicine, Vardhman Mahavir Medical College and Safdarjung \\ Hospital, New Delhi; ${ }^{2}$ Pulmonary Medicine, Medipulse Hospital, Jodhpur; ${ }^{3}$ Community and Family Medicine, All \\ India Institute of Medical Sciences, Jodhpur; ${ }^{4}$ Medeor JCS Institute of Pulmonary, Critical Care and Sleep Medicine, \\ New Delhi, India
}

\begin{abstract}
Heart failure (HF) with preserved ejection fraction (HFpEF) represents nearly half of $\mathrm{HF}$ cases and is increasingly being recognized as a cause of morbidity and mortality. Hypertension (essential or secondary) is an important risk factor of HFpEF, owing to permanent structural changes in heart. A common cause of secondary hypertension is obstructive sleep apnea (OSA). In the present study, we have attempted to seek the frequency and characteristics of sleep disordered breathing (SDB) in HFpEF. Also, we tried to investigate if any correlation exists between the severity
\end{abstract}

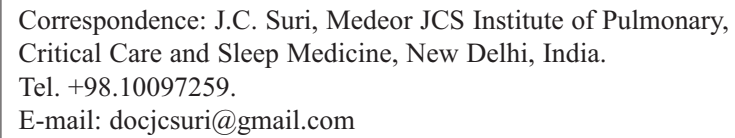
to the conception or design of the work; or the acquisition, analysis, or interpretation of data for the work; drafting the work or revising it critically for important intellectual content; final approval of the version to be published. All the authors agree to be accountable for all aspects of the work in ensuring that questions related to the accuracy or integrity of any part of the work are appropriately investigated and resolved.

Received for publication: 21 April 2020.

Revision received: 7 September 2020.

${ }^{\circ}$ Copyright: the Author(s), 2020

Licensee PAGEPress, Italy

Monaldi Archives for Chest Disease 2020; 90:1329

doi: 10.4081/monaldi.2020.1329

This article is distributed under the terms of the Creative Commons Attribution Noncommercial License (by-nc 4.0) which permits any noncommercial use, distribution, and reproduction in any medium, provided the original author(s) and source are credited. of SDB and the severity of diastolic dysfunction. This was a prospective, cross-sectional, case-control study in which 25 case patients with HFpEF and 25 control subjects were included. All the case patients and control subjects went through a detailed clinical, biochemical, echocardiography evaluation and overnight polysomnography. SDB was seen in $64 \%$ of the case patients having HFpEF and in $12 \%$ of control group with [odds ratio $(\mathrm{OR})=$ $12.2,95 \%$ confidence interval $(\mathrm{CI})=2.83-52.74 ; \mathrm{p}<0.001]$. A significant correlation of apnea hypopnea index (AHI) severity was observed with degree of diastolic dysfunction $(\mathrm{r}=0.67$; $\mathrm{p}<0.001)$. Among HFpEF patients with SDB (16/25), 13 had OSA and only 3 had central sleep apnea (CSA). CSA was present in patients with severe diastolic dysfunction. There were no clinical or sleep quality differences among the OSA and the CSA group. To conclude, higher frequency of SDB is observed in HFpEF patients. AHI severity correlates with degree of diastolic dysfunction. The underlying mechanisms of correlation between SDB and diastolic dysfunction either through uncontrolled hypertension or direct causation warrant further evaluation.

\section{Introduction}

Heart failure (HF) is a common cause of cardiovascular morbidity and mortality and is a global health problem, affecting individuals in both developing and developed countries [1]. Despite improvements in therapy, the mortality rate in patients with HF has remained unacceptably high, making early detection of susceptible persons who would benefit from preventive measures imperative [2].

Epidemiological data have shown that the prevalence of sleep disordered breathing (SDB) is approximately $10 \%$ in the general population. In the heart failure with reduced ejection fraction population (HFrEF), SDB has been identified in up to $75 \%$ of cases, while in heart failure with preserved ejection Fraction (HFpEF), existing data support a prevalence of SDB of approximately $55 \%{ }^{1}$ The Sleep Heart Health Study, a prospective study comprising 6,424 men and women, indicated that the presence of Obstructive sleep apnea (OSA) (defined as an apnea hypopnea index, $\mathrm{AHI} \geq 10$ per $h$ ) favored the appearance of heart failure independently of other known risk factors, with a 2.20 relative risk [3]. The data suggest SDB may be a modifiable risk factor in HFpEF.

It is also hypothesized that the SDB may be associated with the onset and severity of hypertension, degree and severity of diastolic dysfunction, and that SDB may be an amenable factor in the management of HFpEF (Figure 1). A prospective cohort study of 1889 participants, during 21003 person-years of follow-up, in 
comparison with participants without OSA concluded that the presence of OSA was associated with increased adjusted risk of incident hypertension [4]. Fung et al. investigated 68 OSA patients for parameters of diastolic dysfunction and stated that more severe SDB was associated with a higher degree of diastolic dysfunction [5]. Sidana et al. reported diastolic dysfunction was more prevalent in moderate-to-severe OSA [6].

Central sleep apnea (CSA) has been recognized more as a consequence than a cause of HF. The bidirectional relationship has potential therapeutic implications, given the evidence that the treatment of CSA can diminish sympathetic activity. However, the evidence of benefit of treating CSA is not as robust as for OSA. Optimizing treatment of heart failure in CSA is, therefore, more important before attempting positive airway pressure (PAP) therapy.

In the present study, we have attempted to seek the frequency and characteristics of SDB in HFpEF. Also, we tried to investigate, if any correlation exists between the severity of SDB and the severity of diastolic dysfunction.

\section{Methods}

The observational case-control study was carried out over a period of 18 months in the Department of Pulmonary, Critical care and Sleep Medicine, at the tertiary care center in North India. A total of 25 subjects in the age group of $\geq 50$ years, diagnosed with HFpEF were recruited [1]. Exclusion criteria included acute congestive heart failure, acute coronary syndrome, stroke or renal failure. Age and sex matched family members without any cardiac illness and any clinical or echocardiographic evidence of heart failure were recruited as a control group. For the calculation of sample size, we considered the risk of SDB in HFpEF as 55\% and in controls as 10\%. We thus estimated a sample size of 25 per group at $80 \%$ power. Written informed consent was obtained from all the subjects. Institutional Ethical Committee (IEC) clearance was obtained. Data were collected from all the subjects on demographic, clinical (age, sex, sleep history including snoring, choking, sleep disturbances and Epworth Sleepiness Scale self-report), anthropometric (body mass index BMI in $\mathrm{kg} / \mathrm{m}^{2}$ ) and risk factors including arterial hypertension, diabetes mellitus, chronic obstructive pulmonary disease.

Hypertension (HTN) was determined when patients had systolic blood pressure (SBP) $\geq 140 \mathrm{mmHg}$ and/or diastolic blood pressure (DBP) $\geq 90 \mathrm{mmHg}$ for more than two days in the stable phase, and those who were previously diagnosed with hypertension and were receiving hypertensive treatment. The degree of HTN was classified as stage $0 \mathrm{SBP}<140 \mathrm{mmHg}$ and/or $\mathrm{DBP}<90 \mathrm{mmHg}$; Stage $1 \mathrm{SBP}-$ 140-159 mmHg and/or DBP -90-99 mmHg; Stage 2 SBP -160-179 $\mathrm{mmHg}$ and/or DBP 100-109 mmHg; Stage $3 \mathrm{SBP} \geq 180 \mathrm{mmHg}$ and/or DBP $\geq 110 \mathrm{mmHg}$ as per European Society of Cardiology 2018 guidelines [7].

Transthoracic echocardiography (TTE) was done using Epiq 7 (Philips Respironics, USA). Left ventricular ejection fraction (LVEF) measurement was done using modified biplane Simpson's rule [8]. LV end diastolic volume (LVEDV) and LV end systolic volume (LVESV) were obtained from apical four- and two-chamber views and DecT (deceleration time of MV-E); e' (early diastolic tissue velocity); E/e' (a ratio between early mitral inflow velocity and mitral annular early diastolic velocity); IVRT (isovolumetric relaxation time); MV-A (mitral valve late diastolic inflow) and MVE (mitral valve early diastolic inflow) were measured. HFpEF was diagnosed when all the following three conditions were fulfilled [1]: 1. The presence of symptoms and/or signs of HF
2. A 'preserved' EF (defined as LVEF $\geq 50 \%$ or $40-49 \%$ for HFmrEF)

3. Elevated levels of NPs (BNP $>35 \mathrm{pg} / \mathrm{mL}$ and/or NT-pro BNP $>125 \mathrm{pg} / \mathrm{ml}$ ) along with relevant structural heart disease (Left atrial enlargement or left ventricular hypertrophy) or evidence of diastolic dysfunction.

Diastolic dysfunction was documented by a left atrial volume index $(\mathrm{LAVI})>34 \mathrm{ml} / \mathrm{m}^{2}$ or a left ventricular mass index $(\mathrm{LVMI}) \geq 115$ $\mathrm{g} / \mathrm{m}^{2}$ for males and $\geq 95 \mathrm{~g} / \mathrm{m}^{2}$ for females or an $\mathrm{E} / \mathrm{e}^{\prime} \geq 13$ and a mean $\mathrm{e}^{\prime}$ septal and lateral wall $<9 \mathrm{~cm} / \mathrm{s}$. The degree of diastolic dysfunction was classified as per guidelines [1]. The patients underwent overnight, in-laboratory, supervised Polysomnography (PSG) (Alice 6 LDX (Philips Respironics). The scoring was based on the criteria laid down in the International Classification of Sleep Disorders, third edition (ICSD-3). SDB was diagnosed at AHI $>5$ /hour with symptoms of OSA (complains of sleepiness, non-restorative sleep, fatigue) or comorbidities (hypertension, a mood disorder, cognitive dysfunction, coronary artery disease, stroke, congestive heart failure, atrial fibrillation or type 2 diabetes mellitus) [9].

All of the data obtained thereby were recorded systematically using Microsoft office excel and statistical analysis carried out using Statistical Package for Social Sciences version 21. The data were expressed as a mean, standard deviation, frequency and percentage and analyzed using parametric ( $t$-test) and non-parametric (MannWhitney) tests. The correlation was determined using Spearman's coefficient of correlation. Statistically significance was set at 5\% (corresponding to a $\mathrm{p}$-value $\leq 0.05$ ).

\section{Results}

The study cohort consisted of 25 diagnosed patients of HFpEF and 25 age and sex matched controls (healthy subjects). Hypertension (88\%) was a common co-morbidity in HFpEF group. Significant ESS score was not present in either HFpEF patients or controls. However, history of Snoring was present in $64 \%$ of cases. Arterial blood gas analysis revealed a lower oxygen $\left(\mathrm{po}_{2}\right)$ in the HFpEF group along with high lactate (mean of $0.94 \pm 0.13$ as compared to $0.50 \pm 0.06, \mathrm{p}<0.001$ ) levels as compared to controls (Table 1). HFpEF patients in comparison to controls had significantly lower sleep efficiency, longer WASO, longer N1 and N2 with shorter N3 and REM sleep stage (Table 1).

SDB was seen in $64 \%$ of the case patients and in $12 \%$ of control group with $[$ odds ratio $(\mathrm{OR})=12.2,95 \%$ confidence interval $(\mathrm{CI})=$ 2.83-52.74; $\mathrm{p}<0.001]$. Patients with HFpEF and SDB in present study had a higher E/A ratio and a shortened IVRT compared to those without SDB, indicating that SDB may be associated with more severe diastolic dysfunction in HFpEF patients (Table 2). A significant correlation of AHI severity was observed with degree of diastolic dysfunction $(\mathrm{r}=0.67 ; \mathrm{p}<0.001)$. Among HFpEF patients with SDB (16/25), 13 had OSA and 3 had CSA (Table 3). CSA was present in severe diastolic dysfunction patients. However, the sleep quality and arterial blood gas analysis was similar in both OSA and CSA groups (Table 4).

\section{Discussion}

Epidemiologic data have shown that the prevalence of SDB is approximately $10 \%$ in the general population [1]. SDB in HFpEF has been reported in variable frequency among various studies. 
Bitter et al. from Germany, evaluated 244 patients with HFpEF; SDB was documented in 169 patients $(69.3 \%)$, of these 97 patients (39.8\%) presented with OSA [10]. A study by Chan et al., from Hong Kong, showed that $55 \%$ of the patients $(11 / 20)$ had significant SDB; 7 of these patients had predominantly obstructive sleep apnea (OSA) [11]. Herrscher et al., from Norway, have also reported HFpEF patients had SDB in $80 \%$ of the cases, $62 \%$ had OSA [12]. The recent study by Akiwara et al. from Japan, reported presence of SDB in $67 \%$ of 58 patients under evaluation [13]. The criteria used for SDB, the method used for evaluating it and the degree of diastolic dysfunction contributes to these varied figures. In our study, from India, among $25 \mathrm{HFpEF}$ patients, 16 had SDB (64\%), of which 13 had OSA as the major SDB. The proportion of SDB in control group was only $12 \%$; all of them diagnosed as OSA. This was documented by a level 1 PSG in all the patients included in the study.

We tried to seek a correlation between the severity of degree of diastolic dysfunction and SDB. We observed that, with increasing severity of diastolic dysfunction, there was an associated increase in AHI severity, decline in sleep efficiency, along with occurrence of CSA in severe diastolic dysfunction patients. Various studies have indicated that with worsening diastolic dysfunction, SDB worsens. Bitter et al. [10] reported that with increasing impairment of diastolic function, proportion SDB and particularly CSA increased. Fung et al. [5] evaluated 68 OSA patients, reported that more severe SDB was associated with a higher degree of diastolic dysfunction. HF and CSA patients are characterized by a high sympathetic activation during both day and night. This sympathetic activation is linked to the frequency of apneas. Additionally, the frequency and severity of hypoxia through chemoreflex activation contribute to the degree of sympathetic activation. These mechanisms suggest that CSA can have a causative role in worsening the clinical condition of patients with HF, emphasizing the existence of a bidirectional relationship between two conditions.

In past studies, LV wall thickness has been shown to be increased in normotensive patients with OSA $v s$ normotensive control subjects, suggesting that OSA by itself can cause LV hypertrophy and diastolic dysfunction apart from any effect on diurnal systemic BP $[14,15]$. Thus, OSA may have been an etiology of HFpEF in our patients, or may have worsened it by causing hypertension.

Table 1. Baseline characteristics and polysomnographic parameters of cases and controls.

\begin{tabular}{|c|c|c|c|}
\hline Parameters & Cases $(n=25) n(\%)$ & Controls $(\mathrm{n}=25) \mathrm{n}(\%)$ & p \\
\hline $\begin{array}{l}\text { Gender } \\
\text { Male } \\
\text { Female }\end{array}$ & $\begin{array}{c}21(84) \\
4(16)\end{array}$ & $\begin{array}{l}19(76) \\
6(24)\end{array}$ & 0.47 \\
\hline Age (mean \pm SD) (years) & $60.5 \pm 9.8$ & $57.9 \pm 6.5$ & 0.22 \\
\hline BMI $\left(\right.$ mean \pm SD) $\left(\mathrm{kg} / \mathrm{m}^{2}\right)$ & $28.35 \pm 1.62$ & $28.30 \pm 1.24$ & 0.32 \\
\hline Snoring & $16(64.0)$ & $4(16.0)$ & $<0.001$ \\
\hline Hypertension & $25(100)$ & $4(6.25)$ & $<0.001$ \\
\hline Duration of hypertension (mean \pm SD) (years) & $7.2 \pm 2.1$ & $0.2 \pm 0.1$ & $<0.001$ \\
\hline Blood pressure [systolic (mean \pm SD) / diastolic $($ mean \pm SD)] & $148.4 \pm 23.18 / 89.5 \pm 12.8$ & $124.1 \pm 10.2 / 79.6 \pm 5.9$ & 0.016 \\
\hline $\mathrm{pH}(\mathrm{mean} \pm \mathrm{SD})$ & $7.42 \pm 0.02$ & $7.40 \pm 0.02$ & 0.001 \\
\hline $\mathrm{pCO}_{2}($ mean $\pm \mathrm{SD})(\mathrm{mmHg})$ & $37.17 \pm 1.51$ & $40.26 \pm 1.30$ & $<0.05$ \\
\hline $\mathrm{pO}_{2}(\mathrm{mean} \pm \mathrm{SD})(\mathrm{mmHg})$ & $66.45 \pm 2.70$ & $79.28 \pm 6.96$ & $<0.001$ \\
\hline $\mathrm{HCO}_{3^{-}}(\mathrm{mean} \pm \mathrm{SD})(\mathrm{meq} / \mathrm{l})$ & $22.20 \pm 1.14$ & $24.04 \pm 0.80$ & $<0.05$ \\
\hline Lactate $($ mean \pm SD) $(\mathrm{mmol} / \mathrm{l})$ & $0.94 \pm 0.13$ & $0.50 \pm 0.06$ & $<0.001$ \\
\hline NT-ProBNP $($ mean \pm SD) $(\mathrm{pg} / \mathrm{ml})$ & $500.28 \pm 201.73$ & $62.56 \pm 18.31$ & $<0.001$ \\
\hline $\begin{array}{r}\text { PSG (n) } \\
\mathrm{AHI}<5 \\
\mathrm{AHI} \geq 5\end{array}$ & $\begin{array}{l}09(36.0 \%) \\
16(64.0 \%)\end{array}$ & $\begin{array}{l}22(88.0 \%) \\
03(12.0 \%)\end{array}$ & $<0.001$ \\
\hline SDB (AHI $\geq 5+$ signs/symptoms or medical disorder) & $16(88 \%)$ & $3(12 \%)$ & $<0.001$ \\
\hline PSG_TST & $415.64 \pm 9.22$ & $417.88 \pm 14.53$ & 0.518 \\
\hline PSG_sleep_efficiency (\%) & $87.88 \pm 3.38$ & $62.00 \pm 9.95$ & $<0.001$ \\
\hline PSG_sleep_onset (min) & $8.94 \pm 1.63$ & $14.60 \pm 3.04$ & $<0.001$ \\
\hline PSG_WASO (min) & $64.80 \pm 4.25$ & $120.10 \pm 11.98$ & $<0.001$ \\
\hline PSG_N1 (\%TST) & $22.76 \pm 1.31$ & $28.01 \pm 8.18$ & 0.003 \\
\hline PSG_N2 (\%TST) & $42.17 \pm 1.67$ & $54.22 \pm 13.05$ & $<0.001$ \\
\hline PSG_N3 (\%TST) & $22.97 \pm 1.22$ & $10.38 \pm 8.25$ & $<0.001$ \\
\hline PSG_R (\%TST) & $12.16 \pm 2.30$ & $7.45 \pm 3.84$ & $<0.001$ \\
\hline $\mathrm{AHI}($ mean $\pm \mathrm{SD})$ & $7.64 \pm 4.49$ & $2.56 \pm 2.22$ & $<0.001$ \\
\hline $\mathrm{RDI}$ (index) (mean $\pm \mathrm{SD}$ ) & $8.08 \pm 4.40$ & $2.56 \pm 2.22$ & $<0.001$ \\
\hline Snoring episodes (mean \pm SD) & $56.36 \pm 36.44$ & $31.56 \pm 25.00$ & 0.007 \\
\hline Average HR (mean \pm SD) & $84.40 \pm 8.12$ & $69.97 \pm 7.28$ & $<0.001$ \\
\hline
\end{tabular}

BMI, body mass index; $\mathrm{HCO}_{3}$, bicarbonate level; NT, ProBNP-N-terminal pro b-type natriuretic peptide; $\mathrm{HCO}_{3}$, bicarbonate level; PSG, polysomnography; TST, total sleep time; WASO, wake time after sleep onset; AHI, apnea hypopnea index; RDI, respiratory disturbance index. All p-values calculated using Fischer Exact Test. 
In the present study, on evaluation of sleep quality by PSG, HFpEF patients in comparison to controls had similar TST, but had significantly lower sleep efficiency, longer WASO, longer N1 and N2 with shorter N3 and REM sleep stage. This difference in WASO, N1, $\mathrm{N} 2$ and N3 were not seen among the HFpEF with SDB and without SDB groups. The finding is consistent with previous studies [16-18]. ACC/AHA guidelines have identified lack of or poor sleep as a barrier to self-care and treatment adherence in HF patients, providing yet another route to increased risk of morbidity and mortality [1]. The absence of deep sleep, excess stage 1 sleep, and frequent arousals, along with insomnia and wakefulness, collectively could result in increased heart rate and sympathetic activity, with deleterious cardiovascular effect. This state of autonomic imbalance increases blood pressure and heart rate, contributing to the progressive nature of chronic heart failure [19,20].

HFpEF patients with SDB may be candidates for treatment of the underlying SDB with aim to prevent recurrence and improve quality of life. A few recent studies have shown evidence that positive airway pressure (PAP) treatment in patients with $\mathrm{HFpEF}$ and OSA has improved respiratory function (AHI), functional capacity (cardiopulmonary exercise testing), cardiac function and NYHA functional class $[10,18]$. In an observational prospective study by Yoshisha et al., treated $109 \mathrm{HFpEF}$ patients with adaptive servo ventilation (ASV) $(\mathrm{n}=31)$ vs usual care $(\mathrm{n}=78)$, followed up of 6 months and found a decrease in cardiac death and hospitalizations due to cardiac disease $(\mathrm{p}<0.05)$, demonstrating mortality benefit of ASV in HFpEF patients [21]. However, ASV was associated with increased all-cause and cardiovascular mortality in patients who had HFrEF with predominantly central sleep apnea. The ADVENT-HF study is enrolling patients with ejection fraction below or equal to $45 \%$ with OSA (without excessive daytime sleepiness) or CSA [22].

Thus, identifying the predominant SDB, whether OSA or CSA is important as PAP therapy will be the treatment of choice for OSA and will also help in improving cardiac function and functional capacity. Whereas, treating CSA with PAP may or may not be as beneficial for the patient. Differentiating them is best possible by a level 1 PSG with thoracic and abdominal belts to evaluate the effort with the apnea/hypopnea. Most of the reported literature is of home sleep study or a level 3 PSG. Besides, in our study, sleep quality and laboratory parameters in OSA and CSA patients were found comparable as shown in Table 4, thereby providing no potential of predicting the dominant SDB without a PSG.

\section{Limitations and strengths}

A limitation of our study was the small sample size; we had only 25 patients, and we had insufficient numbers for subgroup analysis. We excluded acute heart failure patients; hence our cohort may not be representative of the whole heart failure population seen

Table 2. Polysomnography, arterial blood gas and echocardiography of HFpEF patients with and without sleep disordered breathing.

\begin{tabular}{|c|c|c|c|c|c|}
\hline \multirow[t]{2}{*}{ Variable } & \multicolumn{2}{|c|}{ SDB present $(n=16)$} & \multicolumn{2}{|c|}{ SDB absent(n=9) } & \multirow[t]{2}{*}{ p } \\
\hline & Mean & SD & Mean & SD & \\
\hline Age (years) & 58.7 & 9.5 & 63.7 & 10.0 & 0.228 \\
\hline BMI $\left(\mathrm{kg} / \mathrm{m}^{2}\right)$ & 28.2 & 1.6 & 28.6 & 1.8 & 0.587 \\
\hline Duration (years) & 3.0 & 1.3 & 3.1 & 1.4 & 0.884 \\
\hline $\mathrm{pH}$ & 7.4 & 0.0 & 7.4 & 0.0 & 0.899 \\
\hline $\mathrm{PCO}_{2}(\mathrm{mmHg})$ & 40.3 & 1.5 & 40.0 & 1.6 & 0.609 \\
\hline $\mathrm{PO}_{2}(\mathrm{mmHg})$ & 66.2 & 2.9 & 66.8 & 2.4 & 0.624 \\
\hline $\mathrm{HCO}_{3}(\mathrm{meq} / \mathrm{l})$ & 24.3 & 1.3 & 24.0 & 0.8 & 0.521 \\
\hline Lactate $(\mathrm{mmol} / \mathrm{l})$ & 1.0 & 0.1 & 0.9 & 0.1 & 0.102 \\
\hline NT-ProBNP (pg/ml) & 523.8 & 230.3 & 458.4 & 139.8 & 0.448 \\
\hline PSG_TST (min) & 419.6 & 15.6 & 414.8 & 12.6 & 0.435 \\
\hline PSG_sleep_efficiency (\%) & 58.6 & 7.7 & 68.0 & 11.1 & 0.02 \\
\hline PSG_sleep_onset (min) & 14.1 & 3.1 & 15.4 & 2.9 & 0.323 \\
\hline PSG_WASO (min) & 121.5 & 11.1 & 117.6 & 13.7 & 0.446 \\
\hline PSG_N1 (\%TST) & 27.7 & 8.7 & 28.6 & 7.6 & 0.802 \\
\hline PSG_N2 (\%TST) & 57.9 & 13.3 & 47.6 & 10.2 & 0.055 \\
\hline PSG_N3 (\%TST) & 8.1 & 8.1 & 14.4 & 7.2 & 0.067 \\
\hline PSG_R (\%TST) & 6.2 & 3.2 & 9.6 & 4.2 & 0.033 \\
\hline PSG_A+H (index) & 9.9 & 4.2 & 3.7 & 1.1 & $<0.001$ \\
\hline PSG_snoring episodes & 59.8 & 41.9 & 40.6 & 14.6 & 0.198 \\
\hline PSG_avg HR (/min) & 87.7 & 6.0 & 78.6 & 8.4 & 0.004 \\
\hline Echo_ejection fration (\%) & 55.84 & 2.01 & 52.08 & 3.24 & $<0.001$ \\
\hline Echo_deceleration time (m/s) & 191.52 & 51.23 & 185.52 & 45.74 & 0.664 \\
\hline Echo_early filling/atrial filling $(\mathrm{E} / \mathrm{A})(\mathrm{m} / \mathrm{s})$ & 1.06 & 0.17 & 1.50 & 0.65 & 0.002 \\
\hline Echo_isovolumic relaxation time (m/s) & 135.72 & 19.41 & 84.68 & 27.59 & $<0.001$ \\
\hline
\end{tabular}

SDB, sleep disordered breathing; BMI, body mass index, HCO3, bicarbonate level; NT- ProBNP, N-terminal pro b-type natriuretic peptide; PSG, polysomnography; TST, total sleep time; WASO, wake time after sleep onset; $\mathrm{A}+\mathrm{H}$ - apnea+hypopnea; $\mathrm{HR}$, heart rate. 
Table 3. Obstructive sleep apnea and central sleep apnea patients in HFpEF.

\begin{tabular}{|c|c|c|c|c|c|}
\hline \multirow[t]{2}{*}{ Variable } & & \multicolumn{2}{|c|}{ OSA $(n=13)$} & \multicolumn{2}{|c|}{ CSA $(n=3)$} \\
\hline & & Count & $\%$ & Count & $\%$ \\
\hline Sex & $\begin{array}{l}\text { Male } \\
\text { Female }\end{array}$ & $\begin{array}{c}11 \\
2\end{array}$ & $\begin{array}{l}84.6 \\
15.4\end{array}$ & $\begin{array}{l}2 \\
1\end{array}$ & $\begin{array}{l}66.7 \\
33.3\end{array}$ \\
\hline Dyspnea (NYHA) & $\begin{array}{l}2 \\
3 \\
4 \\
\end{array}$ & $\begin{array}{l}4 \\
6 \\
3\end{array}$ & $\begin{array}{l}30.8 \\
46.2 \\
23.1 \\
\end{array}$ & $\begin{array}{l}0 \\
2 \\
1 \\
\end{array}$ & $\begin{array}{c}0.0 \\
66.7 \\
33.3 \\
\end{array}$ \\
\hline Epworth sleepiness score & $\begin{array}{l}0 \\
1 \\
2 \\
3 \\
4 \\
6\end{array}$ & $\begin{array}{l}9 \\
1 \\
0 \\
1 \\
1 \\
1\end{array}$ & $\begin{array}{c}69.2 \\
7.7 \\
0.0 \\
7.7 \\
7.7 \\
7.7\end{array}$ & $\begin{array}{l}0 \\
1 \\
2 \\
0 \\
0 \\
0\end{array}$ & $\begin{array}{c}0.0 \\
33.3 \\
66.7 \\
0.0 \\
0.0 \\
0.0\end{array}$ \\
\hline SDB_snoring & & 10 & 76.9 & 3 & 100 \\
\hline Choking & & 4 & 30.8 & 2 & 66.7 \\
\hline Sleep disturbance & & 6 & 46.2 & 3 & 100 \\
\hline Hypertension & & 12 & 92.3 & 3 & 100 \\
\hline Stage of hypertension & $\begin{array}{l}0 \\
1 \\
2 \\
3\end{array}$ & $\begin{array}{l}1 \\
7 \\
5 \\
0\end{array}$ & $\begin{array}{c}7.7 \\
53.8 \\
38.5 \\
0.0\end{array}$ & $\begin{array}{l}0 \\
0 \\
2 \\
1\end{array}$ & $\begin{array}{c}0.0 \\
0.0 \\
66.7 \\
33.3\end{array}$ \\
\hline No of drugs for hypertension & $\begin{array}{l}0 \\
1 \\
2 \\
3\end{array}$ & $\begin{array}{c}1 \\
10 \\
2 \\
0\end{array}$ & $\begin{array}{c}7.7 \\
76.9 \\
15.4 \\
0.0\end{array}$ & $\begin{array}{l}0 \\
0 \\
2 \\
1\end{array}$ & $\begin{array}{c}0.0 \\
0.0 \\
66.7 \\
33.3\end{array}$ \\
\hline Grade of diastolic dysfunction & $\begin{array}{l}1 \\
2 \\
3\end{array}$ & $\begin{array}{l}5 \\
5 \\
3\end{array}$ & $\begin{array}{l}38.5 \\
38.5 \\
23.1\end{array}$ & $\begin{array}{l}0 \\
0 \\
3\end{array}$ & $\begin{array}{c}0.0 \\
0.0 \\
100\end{array}$ \\
\hline
\end{tabular}

OSA, obstructive sleep apnea; CSA, central sleep apnea; NYHA, New York Heart Association; SDB, sleep disordered breathing.

Table 4. Arterial blood gas analysis and polysomnography findings of OSA and CSA patients in HFpEF.

\begin{tabular}{|c|c|c|c|c|c|}
\hline \multirow[t]{2}{*}{ Variable } & \multicolumn{2}{|c|}{ OSA $(n=13)$} & \multicolumn{2}{|c|}{ CSA $(n=3)$} & \multirow[t]{2}{*}{ p } \\
\hline & Mean & SD & Mean & SD & \\
\hline Age & 58.4 & 9.8 & 60.0 & 10.0 & 0.801 \\
\hline BMI & 27.9 & 1.6 & 29.4 & 0.6 & 0.142 \\
\hline Duration (years) & 2.9 & 1.1 & 3.5 & 2.2 & 0.493 \\
\hline ABG_pH & 7.4 & 0.0 & 7.4 & 0.0 & 0.835 \\
\hline ABG_PCO 2 & 40.3 & 1.6 & 40.0 & 1.7 & 0.760 \\
\hline ABG_PO ${ }_{2}$ & 66.5 & 2.6 & 64.9 & 4.6 & 0.408 \\
\hline ABG_HCO ${ }_{3}$ & 24.3 & 1.3 & 24.3 & 1.3 & 0.948 \\
\hline Lactate & 1.0 & 0.1 & 1.0 & 0.1 & 0.906 \\
\hline NT-PRoBNP & 471.3 & 218.8 & 751.3 & 122.1 & 0.054 \\
\hline PSG_TST & 417.5 & 14.2 & 428.7 & 21.5 & 0.281 \\
\hline PSG_sleep_efficiency (\%) & 60.2 & 7.2 & 51.7 & 6.7 & 0.082 \\
\hline PSG_sleep_onset (min) & 14.4 & 3.4 & 13.2 & 1.4 & 0.589 \\
\hline PSG_WASO (min) & 121.1 & 12.3 & 123.1 & 2.6 & 0.796 \\
\hline PSG_N1 (\%TST) & 28.2 & 7.0 & 25.3 & 16.2 & 0.620 \\
\hline PSG_N2 (\%TST) & 57.9 & 12.9 & 58.2 & 17.8 & 0.968 \\
\hline PSG_N3 (\%TST) & 7.9 & 8.9 & 9.1 & 4.1 & 0.832 \\
\hline PSG_R (\%TST) & 6.0 & 3.4 & 7.4 & 2.2 & 0.515 \\
\hline PSG_A+H (index) & 9.1 & 4.0 & 13.2 & 3.3 & 0.121 \\
\hline PSG_snoring episodes & 61.8 & 45.5 & 51.0 & 23.9 & 0.700 \\
\hline PSG_avg HR & 87.4 & 5.3 & 89.0 & 10.0 & 0.691 \\
\hline
\end{tabular}

BMI, body mass index; ABG, arterial blood gas analysis; HCO3, bicarbonate level; NT-ProBNP, N-terminal pro b-type natriuretic peptide; PSG, polysomnography; TST, total sleep time; WASO, wake time after sleep onset; $\mathrm{R}$, random eye movement; $\mathrm{A}+\mathrm{H}$ - apnea+hypopnea; $\mathrm{HR}$, heart rate. 
frequently in routine clinical practice. The strength of present study was evaluation was done using level 1 PSG. This allowed for characterization into central and obstructive apneas and labelling the profile on the basis of the dominant disorder. Furthermore, blinded visual analysis of all polysomnographic data was performed at a single center thus minimizing inter-observer variability.

\section{Conclusions}

In conclusion, given the high frequency of SDB, especially OSA, in HFpEF patients, the effects on degree of impairment of diastolic function, and the possibility of improvements with PAP therapy, screening for SDB in all HFpEF patients may be justified, notably in those who have snoring and hypertension. The patients with OSA should be offered PAP therapy in a pursuit of improved outcomes. The SDB must be evaluated by a level 1 PSG as these patients may have co-existing CSA, treatment of which needs to be individualized besides optimizing heart failure medications.

\section{References}

1. Ponikowski P, Voors AA, Anker SD, et al. 2016 ESC Guidelines for the diagnosis and treatment of acute and chronic heart failure. Eur Heart J 2016;37:2129-200.

2. Oldenburg O, Lamp B, Faber L, et al. Sleep-disordered breathing in patients with symptomatic heart failure A contemporary study of prevalence in and characteristics of 700 patients. Eur J Heart Fail 2007;9:251-7.

3. Javaheri S. Sleep dysfunction in heart failure. Curr Treat Options Neurol 2008;10:323-35.

4. Marin J, Agusti A, Villar I, et al. Association between treated and untreated obstructive sleep apnea and risk of hypertension. JAMA 2012;307:2169-76.

5. Fung JWH, Li TST, Choy DKL, et al. Severe obstructive sleep apnea is associated with left ventricular diastolic dysfunction. Chest 2002;121:422-9.

6. Sidana J, Aronow WS, Ravipati G, et al. Prevalence of moderate or severe left ventricular diastolic dysfunction in obese persons with obstructive sleep apnea. Cardiology 2005;104:107-9.

7. Bergler-Klein J. What's new in the ESC 2018 guidelines for arterial hypertension: The ten most important messages. Wien Klin Wochenschr 2019;131:180-5.

8. Russo C, Hahn RT, Jin Z, et al. Comparison of echocardiographic single-plane versus biplane method in the assessment of left atrial volume and validation by real time three-dimensional echocardiography. J Am Soc Echocardiogr 2010;23:954-60.

9. Zucconi M, Ferri R. Assessment of sleep disorders and diagnostic procedures - 1. Classification of sleep disorders. In: C Bassetti, Z Dogas, P Peigneux, editors. ESRS Sleep Medicine Textbook. Regensburg: European Sleep Research Society (ESRS); 2014. pp. 95-109. Accessed on: 20 May 20120. Available from: https://esrs.eu/wp-content/uploads/2018/09/ESRS_Sleep_ Medicine_Textbook_Chapter_B1.pdf

10. Bitter T, Faber L, Hering D, et al. Sleep-disordered breathing in heart failure with normal left ventricular ejection fraction. Eur J Heart Fail 2009;11:602-8.

11. Chan J, Sanderson J, Chan W et al. Prevalence of sleepdisordered breathing in diastolic heart failure. Chest 1997; 111:1488-93.

12. Herrscher TE, Akre H, Øverland B, et al. High prevalence of sleep apnea in heart failure outpatients: Even in patients with preserved systolic function. J Card Fail 2011;17:420-5.

13. Arikawa T, Toyoda S, Haruyama A, et al. Impact of obstructive sleep apnoea on heart failure with preserved ejection fraction. Heart Lung Circ 2016;25:435-4.

14. Agrawal S, Gupta N, Ish P, Chakrabarti S. Sleep disordered breathing in heart failure - A complex bidirectional pathophysiology. Indian Sleep Med 2019;14;70-5.

15. Hedner J, Ejnell H, Caidahl K. Left ventricular hypertrophy independent of hypertension in patients with obstructive sleep apnoea. J Hypertens 1990;8:941-6.

16. Heider K, Arzt M, Lerzer C, et al. Adaptive servo-ventilation and sleep quality in treatment emergent central sleep apnea and central sleep apnea in patients with heart disease and preserved ejection fraction. Clin Res Cardiol 2018;107:421-9.

17. Hetzenecker A, Roth T, Birner C, et al. Adaptive servoventilation therapy of central sleep apnoea and its effect on sleep quality. Clin Res Cardiol 2016;105:189-95.

18. Oldenburg O, Bitter T, Wellmann B, et al. Trilevel adaptive servoventilation for the treatment of central and mixed sleep apnea in chronic heart failure patients. Sleep Med 2013;14:422-7.

19. Mansukhani MP, Kara T, Caples SM, Somers VK. Chemoreflexes, sleep apnea, and sympathetic dysregulation. Curr Hypertens Rep 2014;16:476.

20. Szollosi I, Krum H, Kaye D, Naughton MT. Sleep apnea in heart failure increases heart rate variability and sympathetic dominance. Sleep 2007;30:1509-14.

21. Yoshihisa A, Suzuki S, Yamauchi H, et al. Beneficial effects of positive airway pressure therapy for sleep-disordered breathing in heart failure patients with preserved left ventricular ejection fraction. Clin Cardiol 2015;38:413-21.

22. Bradley TD, Floras JS, ADVENT-HF Investigators. The SERVE-HF Trial. Can Respir J 2015;22:313. 